Trauma Surgery \& Acute Care Open

\title{
Retrospective study on rib fractures: smoking and alcohol matter for mortality and complications
}

\author{
AlleaBelle Gongola 지 , ${ }^{1}$ Jace C Bradshaw, ${ }^{1}$ Jing Jin, ${ }^{1}$ Hanna K Jensen, ${ }^{2}$ Avi Bhavaraju, ${ }^{2}$ \\ Joseph Margolick, ${ }^{2}$ Kevin W Sexton (10, ${ }^{2}$ Ronald Robertson, ${ }^{2}$ Kyle J Kalkwarf (i) ${ }^{2}$
}

1 University of Arkansas for Medical Sciences, Little Rock, Arkansas, USA

2Surgery, University of Arkansas for Medical Sciences, Little Rock Arkansas, USA

Correspondence to Dr AlleaBelle Gongola; alleabelle@hotmail.com

Received 9 March 2021 Accepted 23 May 2021 (c) Author(s) (or their employer(s)) 2021. Re-use permitted under CC BY-NC. No commercial re-use. See rights and permissions. Published by BMJ.

To cite: Gongola A,

Bradshaw JC, Jin J, et al.

Trauma Surg Acute Care Open 2021:6:e000732.

\section{ABSTRACT \\ Background Rib fractures and substance use are both common in trauma patients, but there is little data on how smoking and alcohol use may be associated with outcomes in these patients. We assessed the association between smoking or alcohol use disorder (AUD) and outcomes in patients with rib fractures. \\ Methods We used institutional databases to conduct a retrospective review of patients with rib fractures at the only American College of Surgeons-verified adult level 1 trauma center in a rural state between 2015 and 2019. The key exposure variables were smoking and AUD. The key outcome variables were mortality and pulmonary complications (pneumonia, adult respiratory distress syndrome, and pneumothorax). We used multivariable regression for analysis and directed acyclic graphs to identify variables for adjustment.}

Results We identified 1880 eligible patients with rib fractures, including 693 (37\%) who were smokers and 204 (11\%) who had AUD. Compared with non-smokers, smokers were younger, more often male, and had lower mortality rates. Regression showed that smokers had a lower likelihood of mortality (OR 0.48; 95\% Cl 0.27 to $0.87 ; p=014$ ). Likelihood of pneumonia, ARDS, and pneumothorax was not different between smokers and non-smokers. Compared with patients without AUD, patients with AUD were older, more often male, and had higher likelihood of pneumonia and lower likelihood of pneumothorax. Regression showed that patients with AUD had higher likelihood of pneumonia (OR 1.82; $95 \% \mathrm{Cl} 1.24$ to 2.68; $p=0.002$ ) and lower likelihood of pneumothorax (OR 0.51; 95\% Cl 0.33 to $0.75 ; p=0.002$ ). Discussion In trauma patients with rib fractures treated at a level 1 trauma center over 5 years, smoking was associated with decreased risk of mortality. These findings have implications for risk stratification and clinical decision-making for patients with rib fractures. Level of evidence III

\section{INTRODUCTION}

Rib fractures are diagnosed in approximately 10\% of patients with traumatic injuries. ${ }^{1}$ These injuries are associated with variable rates of mortality $(4 \%$ to $25 \%)$ and pulmonary complications (13\% to 35\%). ${ }^{1-5}$ Many studies have identified risk factors and developed scores and protocols to predict and improve outcomes for these patients because of the potential benefit of accurate risk stratification, given the high frequency and severity of these injuries. ${ }^{6-13}$

Although variables such as age, number of ribs fractured, and comorbidities have been identified as risk factors, ${ }^{14-19}$ smoking and alcohol use disorder
(AUD) have not been studied as thoroughly. A recent Trauma Quality Improvement Program (TQIP) study showed that patients with rib fractures who are smokers have lower rates of mortality than non-smokers $(2.3 \%$ vs $4.6 \% ; \mathrm{p}<0.001),{ }^{20}$ which substantiated previous reports of a 'smoker's paradox', in which smoking appeared to be associated with improved outcomes in trauma patients. ${ }^{21} 22$ Other recent studies showed that alcohol use is associated with higher rates of pneumonia in patients with rib fractures. ${ }^{23}{ }^{24}$ Many of these studies use data from national or urban populations with limited generalizability; our state has unique characteristics compared with the rest of the USA, including a higher percentage of smokers $(23 \%$ vs $14 \%){ }^{25} 26$ Certain subgroups of patients with rib fractures have variable outcomes, ${ }^{2}$ so data from specific populations may be helpful in understanding the associations between smoking and AUD and outcomes.

In this study, we evaluated patients with traumatic rib fractures to determine how smoking and AUD were associated with mortality and pulmonary complications. This study contributes to the need for more data on the smoker's paradox in trauma patients and explores the relationship of AUD and outcomes in patients with rib fractures. Our hypotheses were that smoking would be associated with lower rates of mortality and higher rates of pulmonary complications, ${ }^{220}$ and that AUD would be associated with higher rates of mortality and pulmonary complications. ${ }^{24} 27$ Our goal was to provide insight for risk stratification and clinical decision-making for blunt trauma patients with rib fractures who are smokers or have AUD.

\section{METHODS}

We queried our institutional trauma database at the only American College of Surgeons (ACS)-verified level 1 adult trauma center in the state to identify patients with rib fractures. We cross-referenced these data with our Clinical Data Repository (CDR) to obtain information on pulmonary complications and number of rib fractures.

Patients with rib fractures were identified by Abbreviated Injury Scale (AIS) predot codes. Smoking status and AUD were determined by comorbidity codes from our institution's trauma registry. This registry's data dictionary defines 'smoker' as one who reports smoking cigarettes every day or some days within the last 12 months and defines 'AUD' as a patient who has 'AUD' documented in the medical record. ${ }^{28}$ This documentation 


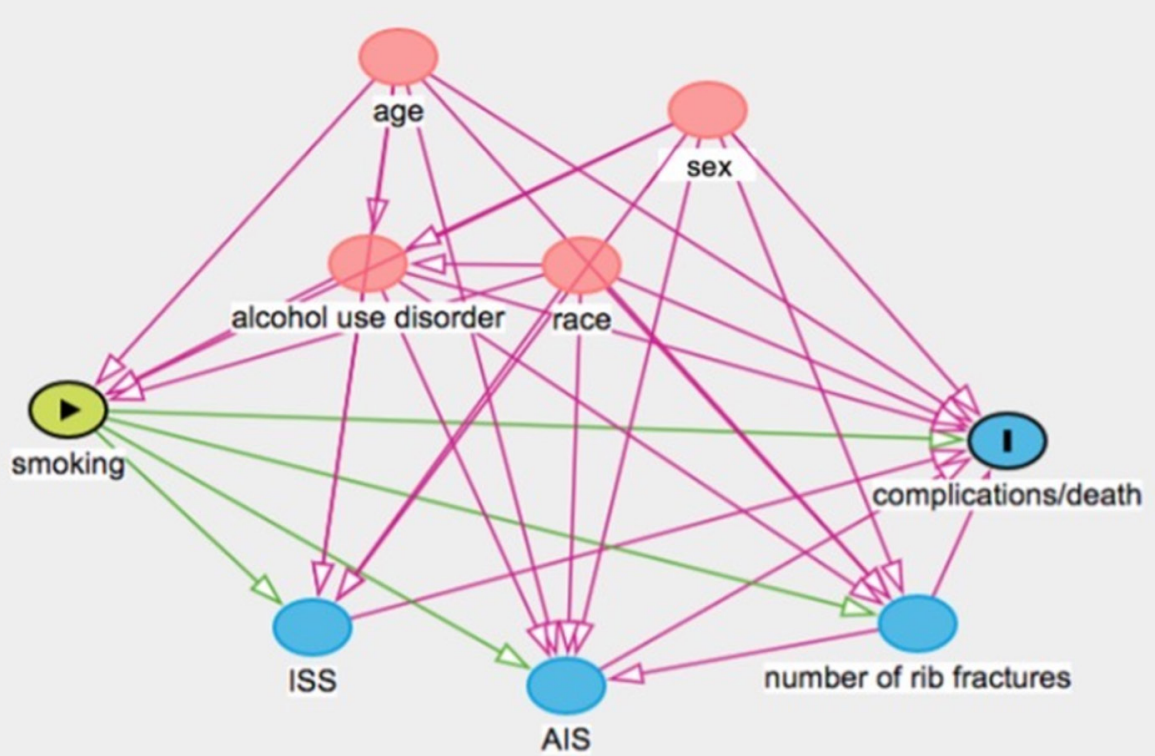

Figure 1 Directed acyclic graph for smoking. Minimal sufficient adjustment sets for estimating the total effect of smoking on complications or death: age, sex, race, and alcohol use. AIS, Abbreviated Injury Scale; ISS, Injury Severity Score.

is generally made by a provider who has taken a complete history and determined that the patient met criteria for the diagnosis based on the reported history of chronic alcohol use. Pulmonary complications and number of ribs fractured were determined by International Classification of Diseases version 10 codes in the CDR. Some patients had a clinical diagnosis of rib fracture(s) without a specified number of fractures, and they were categorized as 'unspecified' for the number of ribs fractured. Patients were included who met the following criteria: clinical diagnosis of one or more ribs fractured, age greater than 17 years, blunt mechanism of injury, year of arrival 2015-2019, and records contained in both the trauma registry and CDR databases. Patients were excluded if they died within 24 hours of admission or had a non-blunt mechanism of injury.
Descriptive analyses were conducted by smoking status or AUD diagnosis for patient characteristics (age, sex, race, smoking status, and AUD diagnosis), injury characteristics (number of ribs fractured, AIS for thorax body region, and Injury Severity Score (ISS)), and outcomes (total hospital days, total intensive care unit (ICU) days, total ventilator days, pulmonary complications, and in-hospital mortality). The pulmonary complications evaluated were pneumonia or ventilator-associated pneumonia (VAP), adult respiratory distress syndrome (ARDS), and pneumothorax. $\mathrm{X}^{2}$ test or Fisher's exact test was used for categorical variables. Student's t-test or Wilcoxon-Mann-Whitney test was used for continuous variables. All categorical variables were described as numbers and percentages. All continuous variables were described as means with SD or medians with IQR.

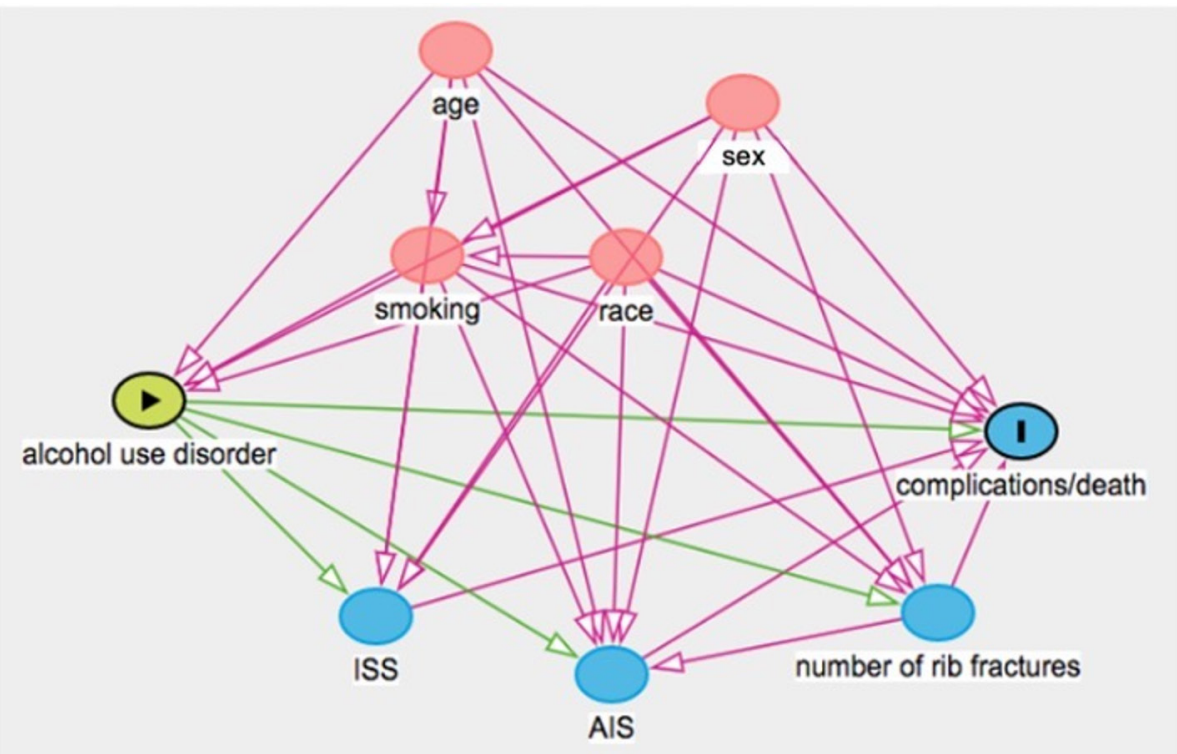

Figure 2 Directed acyclic graph for alcohol use disorder. Minimal sufficient adjustment sets for estimating the total effect of alcohol use disorder on complications or death: age, sex, race, and smoking. AIS, Abbreviated Injury Scale; ISS, Injury Severity Score. 
Multivariable logistic regressions were conducted to assess the association between smoking status or AUD and the risk of pulmonary complications or mortality. Control variables were chosen based on directed acyclic graphs (DAGs). ${ }^{29}$ A DAG is a validated method to identify potential confounders for multivariable regressions that is based on relationships between variables (figures 1 and 2). This method has been increasingly used in health sciences research and is more effective for reducing bias compared with traditional approaches that consider all covariates to be potential confounders and automatically adjust for them. ${ }^{30} 31$ To study the association between smoking and outcomes, we controlled for age, sex, race, and AUD. For the association between AUD and outcomes, we controlled for age, sex, race, and smoking status. Based on previous literature, age, race, and sex were associated with both smoking status and AUD $^{32}$ and each outcome. ${ }^{33}$ Smoking status was associated with AUD. ${ }^{34}$ Number of ribs fractured, ISS, and AIS body region score were intermediates that were not considered as confounders in the association between smoking status or AUD and pulmonary complications or mortality outcomes. Statistical significance was assumed at $\alpha<0.05$. All analyses were performed on SAS V.9.4 (SAS Institute).

\section{RESULTS}

The initial query of our trauma database identified 2112 patients with one or more ribs fractured who were admitted to our ACS-verified level 1 adult trauma center from 2015 through 2019. After exclusions, the final cohort was composed of 1880 patients: 693 (36.9\%) were smokers and 204 (10.9\%) had AUD. No data were missing from the key exposure variables and minimal data were missing from demographic variables. Missing data were excluded from tables 1 and 2 . The variable with the highest amount of missing data was age, which was missing in $1.3 \%$ of patients.

\section{Smoking status}

In a comparison of smokers and non-smokers using bivariate analysis, smokers were younger, more often male, and more likely to have AUD (table 1). Smokers had a lower rate of in-hospital mortality $(2.2 \%$ vs $4.8 \%$; $=0.004)$ (table 1$)$. In a multivariable regression comparing smokers with non-smokers, the likelihood of pneumonia or VAP, ARDS, or pneumothorax was not significantly different after adjusting for age, sex, race, and AUD (table 2). Mortality was 52\% less likely among smokers compared with non-smokers (OR 0.48 ; 95\% CI 0.27 to 0.87 ; $\mathrm{p}=0.014$ ) in an adjusted model (table 2 ).

\section{Alcohol use disorder}

In comparing patients with AUD with those without AUD using bivariate analysis, patients with AUD were older, more often male, and more likely to be smokers (table 3). Patients with AUD also had different numbers of ribs fractured; different AIS thorax body region scores and spent more days in the hospital, in the ICU, and on the ventilator. Patients with AUD had higher rates of pneumonia $(19.6 \%$ vs $11.8 \%$; $=0.002)$ and lower rates of pneumothorax $(12.7 \%$ vs $22.3 \% ; p=0.002)$ (table 3$)$. In a multivariable regression comparing patients with and without AUD for the likelihood of pulmonary complications with adjustment for age, sex, race, and smoking status, patients with AUD had a higher likelihood of pneumonia or VAP (OR 1.82; 95\% CI 1.24 to $2.68 ; \mathrm{p}=0.002)$ and a lower likelihood of pneumothorax (OR $0.51 ; 95 \%$ CI 0.33 to $0.75 ; \mathrm{p}=0.002)$. AUD diagnosis was not significantly associated with likelihood of ARDS (table 4). The
Table 1 Descriptive analysis for demographics and outcomes in patients with traumatic rib fractures based on smoking status

\begin{tabular}{|c|c|c|c|}
\hline & $\begin{array}{l}\text { Smoker } \\
(\mathrm{n}=693)\end{array}$ & $\begin{array}{l}\text { Non-smoker } \\
(n=1187)\end{array}$ & $P$ value \\
\hline \multicolumn{4}{|l|}{ Age $^{*}$} \\
\hline $18-45$ & 337 (48.6) & 402 (34.6) & $<0.001$ \\
\hline $46-64$ & $276(39.8)$ & $418(35.9)$ & \\
\hline $65+$ & $80(11.6)$ & $343(29.5)$ & \\
\hline Mean & $46 \pm 15$ & $53 \pm 18$ & $<0.001$ \\
\hline \multicolumn{4}{|l|}{ Sex } \\
\hline Male & 505 (72.9) & $783(66.0)$ & 0.002 \\
\hline \multicolumn{4}{|l|}{ Race* $^{*}$} \\
\hline White & $540(78.0)$ & $921(77.7)$ & 0.106 \\
\hline Black or African American & $129(18.7)$ & $201(17.0)$ & \\
\hline Others & $23(3.3)$ & $63(5.3)$ & \\
\hline \multicolumn{4}{|l|}{ Smoker } \\
\hline Alcohol use disorder & $115(16.6)$ & $89(7.5)$ & $<0.001$ \\
\hline \multicolumn{4}{|l|}{ Number of ribs fractured } \\
\hline Single & $75(10.8)$ & $152(12.8)$ & 0.277 \\
\hline Multiple & $342(49.3)$ & $609(51.3)$ & \\
\hline Flail & $6(0.9)$ & $12(1.0)$ & \\
\hline Unspecified & $270(39.0)$ & $414(34.9)$ & \\
\hline AIS thorax body region & $3(2-3)$ & $3(2-3)$ & 0.439 \\
\hline ISS & $17(13-27)$ & $17(12-26)$ & 0.085 \\
\hline Hospital days & $5(2-11)$ & $5(2-11)$ & 0.348 \\
\hline ICU days & $0(0-5)$ & $1(0-5)$ & 0.347 \\
\hline Ventilator days & $0(0-2)$ & $0(0-2)$ & 0.542 \\
\hline Pneumonia or VAP & $86(12.4)$ & $152(12.8)$ & 0.804 \\
\hline ARDS & $33(4.8)$ & $43(3.6)$ & 0.226 \\
\hline Pneumothorax & $160(23.1)$ & $239(20.1)$ & 0.131 \\
\hline Mortality & $15(2.2)$ & $57(4.8)$ & 0.004 \\
\hline
\end{tabular}

Results are presented as $n(\%)$, mean $\pm S D$, or median $(I Q R)$, as appropriate. * Missing data are not included in the summary.

AIS, Abbreviated Injury Scale; ARDS, adult respiratory distress syndrome; ICU, intensive care unit; ISS, Injury Severity Score; VAP, ventilator-associated pneumonia.

likelihood of mortality was not significantly different among patients with and without AUD in an adjusted model (table 4).

\section{DISCUSSION}

Our findings from a retrospective, single-institution database study over 5 years confirmed previous studies that in patients with rib fractures caused by blunt trauma, smoking was associated with a decreased risk of mortality and AUD was associated with an increased risk of pneumonia. We also found that AUD

Table 2 Multivariable logistic regression for the risk of pulmonary complications and mortality based on smoking status in patients with traumatic rib fractures

\begin{tabular}{llll} 
& OR & $95 \% \mathrm{Cl}$ & P value \\
\hline $\begin{array}{llll}\text { Smokers* } \\
\text { Pneumonia or VAP }\end{array}$ & 0.90 & 0.67 to 1.21 & 0.473 \\
ARDS & 1.38 & 0.86 to 2.21 & 0.180 \\
Pneumothorax & 1.12 & 0.88 to 1.41 & 0.350 \\
Mortality & 0.48 & 0.27 to 0.87 & 0.014 \\
\hline
\end{tabular}

*Adjusted for age (as continuous variable), sex, race, and alcohol use disorder. ARDS, adult respiratory distress syndrome; VAP, ventilator-associated pneumonia. 
Table 3 Descriptive analysis for demographics and outcomes in patients with traumatic rib fractures based on alcohol use disorder diagnosis

\begin{tabular}{|c|c|c|c|}
\hline & $\begin{array}{l}\text { Alcohol use disorder } \\
(n=204)\end{array}$ & $\begin{array}{l}\text { No alcohol use } \\
\text { disorder } \\
(n=1676)\end{array}$ & $P$ value \\
\hline \multicolumn{4}{|l|}{ Age $^{*}$} \\
\hline $18-45$ & 64 (31.4) & $675(40.9)$ & 0.028 \\
\hline $46-64$ & $90(44.1)$ & $604(36.5)$ & \\
\hline $65+$ & $50(24.5)$ & $373(22.6)$ & \\
\hline Mean & $53 \pm 16$ & $50(18)$ & 0.005 \\
\hline \multicolumn{4}{|l|}{ Sex } \\
\hline Male & $164(80.4)$ & $1124(67.1)$ & $<0.001$ \\
\hline \multicolumn{4}{|l|}{ Race* } \\
\hline White & $160(78.4)$ & $1301(77.8)$ & 0.059 \\
\hline $\begin{array}{l}\text { Black or African } \\
\text { American }\end{array}$ & $41(20.1)$ & $289(17.3)$ & \\
\hline Others & $3(1.5)$ & $83(4.9)$ & \\
\hline Smoker & $115(56.4)$ & $578(34.5)$ & $<0.001$ \\
\hline \multicolumn{4}{|l|}{ Alcohol use disorder } \\
\hline \multicolumn{4}{|l|}{ Number of ribs fractured } \\
\hline Single & $35(17.2)$ & $192(11.5)$ & 0.002 \\
\hline Multiple & $78(38.2)$ & $873(52.1)$ & \\
\hline Flail & $3(1.5)$ & $15(0.9)$ & \\
\hline Unspecified & $88(43.1)$ & $596(35.5)$ & \\
\hline AIS thorax body region & $3(2-3)$ & $3(2-3)$ & 0.044 \\
\hline ISS & $17(13-24)$ & $17(12-26)$ & 0.450 \\
\hline Hospital days & $7(3-13)$ & $5(2-11)$ & $<0.001$ \\
\hline ICU days & $3(0-8)$ & $0(0-4)$ & $<0.001$ \\
\hline Ventilator days & $0(0-3)$ & $0(0-2)$ & 0.013 \\
\hline Pneumonia or VAP & $40(19.6)$ & $198(11.8)$ & 0.002 \\
\hline ARDS & $5(2.4)$ & $71(4.2)$ & 0.222 \\
\hline Pneumothorax & $26(12.7)$ & $373(22.3)$ & 0.002 \\
\hline Mortality & $8(3.9)$ & $64(3.8)$ & 0.942 \\
\hline
\end{tabular}

Results are presented as $n(\%)$, mean $\pm S D$, or median (IQR), as appropriate. ${ }^{*}$ Missing data are not included in the summary.

AIS, Abbreviated Injury Scale; ARDS, adult respiratory distress syndrome; ICU, intensive care unit; ISS, Injury Severity Score; VAP, ventilator-associated pneumonia.

was associated with a decreased risk of pneumothorax. These results were based on regression analyses controlling for demographic variables of age, sex, race, and smoking or AUD. Previous studies have shown that pulmonary complications and mortality are associated with ISS and number of ribs fractured. ${ }^{135} \mathrm{We}$ did

Table 4 Multivariable logistic regression for the risk of pulmonary complications and mortality based on alcohol use disorder diagnosis in patients with traumatic rib fractures

\begin{tabular}{llll}
\hline & OR & $95 \% \mathrm{Cl}$ & P value \\
\hline Alcohol use disorder $^{*}$ & & & \\
\hline Pneumonia or VAP & 1.82 & 1.24 to 2.68 & 0.002 \\
ARDS & 0.57 & 0.24 to 1.39 & 0.216 \\
Pneumothorax & 0.51 & 0.22 to 0.78 & 0.002 \\
Mortality & 1.12 & 0.53 to 2.34 & 0.771 \\
\hline
\end{tabular}

${ }^{*}$ Adjusted for age (as continuous variable), sex, race, and smoking status. ARDS, adult respiratory distress syndrome; VAP, ventilator-associated pneumonia. not control for these variables because we only controlled for covariates that were known confounders, not intermediates.

Grigorian et al performed a retrospective analysis of the TQIP database and found that smokers with rib fractures experienced nearly a $40 \%$ decreased risk of in-hospital mortality compared with non-smokers $(p<0.05)$, despite having higher rates of pneumonia. ${ }^{20}$ Our findings reinforce that smoking is associated with a decreased risk of in-hospital mortality $(\mathrm{p}<0.05)$. Our results differed from Grigorian et al when examining pneumonia rates between these two groups; we found that patients who smoked were no more likely to get pneumonia than non-smoking patients. This result supports the conclusions of a single-center retrospective study by Marco et al, which determined that smoking was not associated with increased risk of pneumonia in patients with traumatic rib fractures. ${ }^{23}$

Previous research has demonstrated a 'smoker's paradox': smokers with cardiovascular disease have improved outcomes compared with non-smokers with similar disease. ${ }^{36-38}$ Studies examining trauma patients who smoke demonstrated that smoking did not increase risk of pneumonia, ARDS, or mortality. ${ }^{21} 2239$ Our study provides additional support that the smoker's paradox may exist in patients hospitalized with rib fractures. Hypothesized pathophysiologic mechanisms to explain these findings have focused on the demonstrated effects of cigarette smoke or its individual components, including nicotine and carbon monoxide (CO). Nicotine acts as a vasoconstrictor in the peripheral vasculature by direct action and by promoting release of epinephrine and norepinephrine, ${ }^{40-42}$ which could be responsible for maintaining blood pressure and limiting blood loss. ${ }^{43-45} \mathrm{CO}$ may also have contributory vasoactive effects. ${ }^{4142}$ The hemostatic effects of cigarette smoking could also contribute to the smoker's paradox in trauma patients. ${ }^{22}$ Cigarette smoke promotes coagulation through platelet activation, ${ }^{46-48}$ effects on blood cells and components, ${ }^{41}{ }^{49}$ and endothelial changes. ${ }^{50-52}$ Finally, the anti-inflammatory effects of nicotine could contribute to the paradox..$^{53} 54$ When considered together, these mechanisms provide a plausible explanation for the physiologic and biochemical mechanisms of the reduction of in-hospital mortality in this population.

Chronic alcohol exposure is associated with pneumonia and other adverse outcomes in trauma patients..$^{27}$ Recent studies of trauma patients with rib fractures have shown an association between AUD and higher rates of pneumonia. ${ }^{23}{ }^{24}$ Vartan et al also found an association with AUD and higher rates of ARDS and mortality. ${ }^{24}$ Our results support previous findings of an association between AUD and higher rates of pneumonia; however, we did not observe a higher rate of ARDS, potentially due to low incidence. Our results showed that patients with AUD had a trend toward increased risk of in-hospital mortality, but the association was not statistically significant. Marco et al found no association of pneumothorax in patients with AUD, ${ }^{23}$ but we found a lower rate of pneumothorax in patients with AUD. Possible explanations for the discrepancy are that their sample size was smaller $(n=152)$ or that the two populations were different in terms of risk factors for pneumothorax that were not measured. Our results add to another recent study that found a surprising inverse relationship between pneumothorax and mortality in patients with rib fractures. ${ }^{2}$ These findings could be associated with statistical limitations of retrospective design.

There are established associations between AUD and pneumonia or pulmonary inflammation. ${ }^{55}$ Proposed pathophysiologic mechanisms for this association are multifaceted: increased risk of aspiration, ${ }^{56}$ decreased upper-airway mucociliary clearance of bacterial pathogens, ${ }^{57}$ and impaired pulmonary host defenses. ${ }^{58-60}$ 
Inflammation can be further exacerbated in this demographic because of a diminished ability to manage oxidative stress and reduced ability to tolerate the fluid accumulation associated with trauma or pneumonia. ${ }^{6162}$

A limitation of our study is the possibility of uncontrolled covariates acting as confounders. We made a concerted effort to mitigate this limitation by using DAGs to identify relationships between variables (figures 1 and 2). We chose to control for confounders and not to control for mediators (ie, ISS). Controlling for covariates that are not confounders increases the risk of collider bias or switchover effects, which we hoped to avoid. ${ }^{63}{ }^{64}$ The limitation caused by control variable selection has been discussed specifically in the context of the smoker's paradox. ${ }^{65}$ As with any retrospective study, unmeasured covariates could have affected the results. These could include certain comorbidities (eg, chronic obstructive pulmonary disease), vital signs (eg, heart rate and blood pressure), and Glasgow Coma Scale. Another limitation associated with the retrospective design is that missing data or inaccurate documentation or coding may have affected the results. We identified patients as smokers or AUD based on patient charts, which are subject to missing or inaccurate data. We did not evaluate the quantity of smoking or alcohol use for each patient, which is an important consideration for future research. Additionally, analysis of some less common complications may have been limited by sample size. Finally, this study was conducted at a single institution in a rural state and results may not be generalizable to other settings.

The results of the primary objective of this study fit within existing literature. We isolated a unique patient population because the study site is the only ACS-verified level 1 trauma center in a rural state. This population has distinct characteristics and is relatively under-represented in national databases, but our results were similar to previous studies. This replication establishes a strong basis for the external validity of our analysis and the generalizability of these findings to other similarly situated trauma centers. To maintain internal validity, multivariate analysis controlling for confounders identified by DAGs was used.

Future research should continue to isolate demographics that are under-represented in national trauma databases to further improve the generalizability of current rib fracture analyses. There is also a need to examine more patient characteristics and injury factors to establish reliable predictors for outcomes. Finally, basic science research is needed to evaluate the mechanisms of unexpected findings in recent retrospective studies, including the associations between smoking and mortality.

\section{CONCLUSIONS}

Our study found that in patients with rib fractures caused by blunt trauma, smoking was associated with decreased mortality and AUD was associated with increased risk of pneumonia. Additional studies are needed to further investigate the relationship between these exposures and outcomes in patients with rib fractures.

Acknowledgements The authors would like to acknowledge the contributions of Ms Judy Bennett, Ms Monica Kimbrell with UAMS Trauma Registry database, and the UAMS Translational Research Institute.

Contributors $A G$ and JCB performed the literature search, conceptualization, and writing of the manuscript. JJ performed statistical analysis and writing. $H K J, A B$, $J M, K W S$, and RR contributed to study design, conceptualization, and editing. KJK oversaw the project, including study design, conceptualization, methodology, and editing.

Funding The authors have not declared a specific grant for this research from any funding agency in the public, commercial or not-for-profit sectors.
Competing interests None declared.

Patient consent for publication Not required.

Ethics approval Ethics approval was obtained from the Institutional Review Board at the University of Arkansas for Medical Sciences (IRB 260130). Informed consent was not required, as this was a retrospective analysis of a deidentified dataset.

Provenance and peer review Not commissioned; externally peer reviewed. Data availability statement No data are available.

Open access This is an open access article distributed in accordance with the Creative Commons Attribution Non Commercial (CC BY-NC 4.0) license, which permits others to distribute, remix, adapt, build upon this work non-commercially, and license their derivative works on different terms, provided the original work is properly cited, appropriate credit is given, any changes made indicated, and the use is non-commercial. See: http://creativecommons.org/licenses/by-nc/4.0/.

\section{ORCID iDs}

AlleaBelle Gongola http://orcid.org/0000-0002-2984-0578

Kevin W Sexton http://orcid.org/0000-0002-1460-9867

Kyle J Kalkwarf http://orcid.org/0000-0003-1693-4935

\section{REFERENCES}

1 Flagel BT, Luchette FA, Reed RL, Esposito TJ, Davis KA, Santaniello JM, Gamelli RL. Half-a-dozen ribs: the breakpoint for mortality. Surgery 2005;138:717-25.

2 Peek J, Ochen Y, Saillant N, Groenwold RHH, Leenen LPH, Uribe-Leitz T, Houwert RM, Heng M. Traumatic rib fractures: a marker of severe injury. A nationwide study using the National trauma data bank. Trauma Surg Acute Care Open 2020;5:e000441.

3 Brasel KJ, Guse CE, Layde P, Weigelt JA. Rib fractures: relationship with pneumonia and mortality. Crit Care Med 2006;34:1642-6.

4 Martin TJ, Eltorai AS, Dunn R, Varone A, Joyce MF, Kheirbek T, Adams C, Daniels AH, Eltorai AEM. Clinical management of rib fractures and methods for prevention of pulmonary complications: a review. Injury 2019;50:1159-65.

5 Ziegler DW, Agarwal NN. The morbidity and mortality of rib fractures. J Trauma 1994;37:975-9.

6 Pape HC, Remmers D, Rice J, Ebisch M, Krettek C, Tscherne H. Appraisal of early evaluation of blunt chest trauma: development of a standardized scoring system for initial clinical decision making. J Trauma 2000;49:496-504.

7 Easter A. Management of patients with multiple rib fractures. Am J Crit Care 2001:10:320-7.

8 Todd SR, McNally MM, Holcomb JB, Kozar RA, Kao LS, Gonzalez EA, Cocanour CS, Vercruysse $\mathrm{GA}$, Lygas $\mathrm{MH}$, Brasseaux $\mathrm{BK}$, et al. A multidisciplinary clinical pathway decreases rib fracture-associated infectious morbidity and mortality in high-risk trauma patients. Am J Surg 2006;192:806-11.

9 Maxwell CA, Mion LC, Dietrich MS. Hospitalized injured older adults: clinical utility of a rib fracture scoring system. J Trauma Nurs 2012;19:168-74.

10 Hardin KS, Leasia KN, Haenel J, Moore EE, Burlew CC, Pieracci FM. The sequential clinical assessment of respiratory function (Scarf) score: a dynamic pulmonary physiologic score that predicts adverse outcomes in critically ill rib fracture patients. 2019;87:1260-8

11 Pressley CM, Fry WR, Philp AS, Berry SD, Smith RS. Predicting outcome of patients with chest wall injury. Am J Surg 2012;204:910-4.

12 Witt CE, Bulger EM. Comprehensive approach to the management of the patient with multiple rib fractures: a review and introduction of a bundled rib fracture management protocol. Trauma Surg Acute Care Open 2017:2:1-7.

13 Battle C, Hutchings H, Lovett S, Bouamra O, Jones S, Sen A, Gagg J, Robinson D, Hartford-Beynon J, Williams J, et al. Predicting outcomes after blunt chest wall trauma: development and external validation of a new prognostic model. Crit Care 2014:18:1-8.

14 Demetriades D, Sava J, Alo K, Newton E, Velmahos GC, Murray JA, Belzberg H, Asensio JA, Berne TV. Old age as a criterion for trauma team activation. J Trauma 2001:51:754-6.

15 Bulger EM, Arneson MA, Mock CN, Jurkovich GJ. Rib fractures in the elderly. J Trauma 2000;48:1040-7.

16 Holcomb JB, McMullin NR, Kozar RA, Lygas MH, Moore FA. Morbidity from rib fractures increases after age 45. J Am Coll Surg 2003:196:549-55.

17 Grossman MD, Miller D, Scaff DW, Arcona S. When is an elder old? effect of preexisting conditions on mortality in geriatric trauma. J Trauma 2002;52:242-6.

18 Bergeron E, Lavoie A, Clas D, Moore L, Ratte S, Tetreault S, Lemaire J, Martin M. Elderly trauma patients with rib fractures are at greater risk of death and pneumonia. J Trauma 2003;54:478-85

19 FCF L, RY L, Tung YW, Jeng KC, Morbidity TSCS. Mortality, associated injuries, and management of traumatic rib fractures. J Chinese Med Assoc 2016;79:329-34.

20 Grigorian A, Lekawa M, Dolich M, Schubl SD, Doben AR, Kuza CM, Barrios C, Nahmias J. Smoking is associated with an improved short-term outcome in patients with rib fractures. Eur J Trauma Emerg Surg 2020;46:927-33. 
21 Ferro TN, Goslar PW, Romanovsky AA, Petersen SR. Smoking in trauma patients: the effects on the incidence of sepsis, respiratory failure, organ failure, and mortality. $J$ Trauma 2010;69:308-11.

22 Bell TM, Bayt DR, Zarzaur BL. "Smoker's Paradox" in Patients Treated for Severe Injuries: Lower Risk of Mortality After Trauma Observed in Current Smokers. Nicotine Tob Res 2015;17:1499-504.

23 Marco CA, Sorensen D, Hardman C, Bowers B, Holmes J, McCarthy MC. Risk factors for pneumonia following rib fractures. Am J Emerg Med 2020;38:610-2.

24 Vartan P, Asmar S, Bible L, Chehab M, Khurrum M, Castanon L, Ditillo M, Joseph B. Alcohol Use Disorder Is Bad for Broken Ribs: A Nationwide Analysis of 19,638 Patients With Rib Fractures. J Surg Res 2020;255:556-64.

25 Centers for Disease Control and Prevention. Burden of Cigarette Use in the U.S. https://www.cdc.gov/tobacco/campaign/tips/resources/data/cigarette-smoking-inunited-states.html (24 Apr 2021).

26 Centers for Disease Control and Prevention. Current cigarette use among adults (behavioral risk factor surveillance system), 2018.

27 Jurkovich GJet al. The effect of acute alcohol intoxication and chronic alcohol abuse on outcome from trauma. JAMA 1993;270:51-6.

28 Arkansas Department of Health. Arkansas trauma registry data dictionary. 2019. https://www.dfa.arkansas.gov/images/uploads/osp-anticipation-to-award/AttachA ARTraumaDataDictionary.pdf (6 Mar 2021).

29 Tennant PWG, Murray EJ, Arnold KF, Berrie L, Fox MP, Gadd SC, Harrison WJ, Keeble C, Ranker LR, Textor J, et al. Use of directed acyclic graphs (DAGs) to identify confounders in applied health research: review and recommendations. Int J Epidemiol 2021;50:620-32.

30 Gaskell AL, Sleigh JW. An introduction to causal diagrams for anesthesiology research. Anesthesiology 2020;132:951-67.

31 Shrier I, Platt RW. Reducing bias through directed acyclic graphs. BMC Med Res Methodol 2008;8:1-15.

32 Caraballo RS, Sharapova SR, Asman KJ. Does a Race-Gender-Age crossover effect exist in current cigarette smoking between non-Hispanic blacks and non-Hispanic whites? United States, 2001-2013. Nicotine Tob Res 2016;18 Suppl 1:S41-8.

33 Tignanelli CJ, Hemmila MR, Rogers MAM, Raghavendran K. Nationwide cohort study of independent risk factors for acute respiratory distress syndrome after trauma. Trauma Surg Acute Care Open 2019;4:1-9.

34 Falk DE, Yi H-ye, Hiller-Sturmhöfel S. An epidemiologic analysis of co-occurring alcohol and tobacco use and disorders: findings from the National epidemiologic survey on alcohol and related conditions. Alcohol Res Health 2006;29:162-71.

35 Harrington DT, Phillips B, Machan J, Zacharias N, Velmahos GC, Rosenblatt MS, Winston E, Patterson L, Desjardins S, Winchell R, et al. Factors associated with survival following blunt chest trauma in older patients: results from a large regional trauma cooperative. Arch Surg 2010;145:432-7.

36 Ali SF, Smith EE, Bhatt DL, Fonarow GC, Schwamm LH. Paradoxical association of smoking with in-hospital mortality among patients admitted with acute ischemic stroke. J Am Heart Assoc 2013;2:10-13.

37 Purcell IF, Newall N, Farrer M. Lower cardiac mortality in smokers following thrombolysis for acute myocardial infarction may be related to more effective fibrinolysis. QJM 1999;92:327-33.

38 Ovbiagele B, Saver JL. The smoking-thrombolysis paradox and acute ischemic stroke. Neurology 2005:65:293-5.

39 Resnick S, Inaba K, Okoye O, Nosanov L, Grabo D, Benjamin E, Smith J, Demetriades D. Impact of smoking on trauma patients. Ulus Travma Acil Cerrahi Derg 2014;20:248-52.

40 Benowitz NL, Burbank AD. Cardiovascular toxicity of nicotine: implications for electronic cigarette use. Trends Cardiovasc Med 2016;26:515-23.

41 U.S. Department of Health and Human Services. How tobacco smoke causes disease the biology and behavioral basis for Smoking-Attributable disease a report of the surgeon General. Rockville, MD, 2010.
42 Toda N, Toda H. Nitric oxide-mediated blood flow regulation as affected by smoking and nicotine. Eur J Pharmacol 2010;649:1-13.

43 Poloujadoff M-P, Borron SW, Amathieu R, Favret F, Camara MS, Lapostolle F, Vicaut E, Adnet F. Improved survival after resuscitation with norepinephrine in a murine model of uncontrolled hemorrhagic shock. Anesthesiology 2007;107:591-6.

44 Bougié A, Harrois A, Duranteau J. Resuscitative strategies in traumatic hemorrhagic shock. Ann Intensive Care 2013;3:1-9.

45 Beloncle F, Meziani F, Lerolle N, Radermacher P, Asfar P. Does vasopressor therapy have an indication in hemorrhagic shock? Ann Intensive Care 2013;3:1-6.

46 Glynn MF, Mustard JF, Buchanan MR, Murphy EA. Cigarette smoking and platelet aggregation. Can Med Assoc J 1966;95:549-53.

47 Nielsen VG, Hafner DT, Steinbrenner EB. Tobacco smoke-induced hypercoagulation in human plasma: role of carbon monoxide. Blood Coagul Fibrinolysis 2013;24:405-10.

48 Rubenstein D, Jesty J, Bluestein D. Differences between mainstream and sidestream cigarette smoke extracts and nicotine in the activation of platelets under static and flow conditions. Circulation 2004;109:78-83.

49 Matetzky S, Tani S, Kangavari S, Dimayuga P, Yano J, Xu H, Chyu KY, Fishbein MC, Shah PK, Cercek B. Smoking increases tissue factor expression in atherosclerotic plaques: implications for plaque thrombogenicity. Circulation 2000;102:602-4.

50 Neunteufl T, Heher S, Kostner K, Mitulovic G, Lehr S, Khoschsorur G, Schmid RW, Maurer $\mathrm{G}$, Stefenelli T. Contribution of nicotine to acute endothelial dysfunction in long-term smokers. J Am Coll Cardiol 2002;39:251-6.

51 Flouris AD, Vardavas Cl, Metsios GS, Tsatsakis AM, Koutedakis Y. Biological evidence for the acute health effects of secondhand smoke exposure. Am J Physiol Lung Cell Mol Physiol 2010;298:L3-L12.

52 Lee J, Cooke JP. The role of nicotine in the pathogenesis of atherosclerosis. Atherosclerosis 2011;215:281-3.

53 Wittebole X, Hahm S, Coyle SM, Kumar A, Calvano SE, Lowry SF. Nicotine exposure alters in vivo human responses to endotoxin. Clin Exp Immunol 2007;147:28-34.

54 Wedn AM, El-Gowilly SM, El-Mas MM. Nicotine improves survivability, hypotension, and impaired adenosinergic renal vasodilations in endotoxic rats: role of $\alpha 7-n A C h R s /$ HO-1 pathway. Shock 2020;53:503-13.

55 Simou E, Britton J, Leonardi-Bee J. Alcohol and the risk of pneumonia: a systematic review and meta-analysis. BMJ Open 2018;8:e022344-10.

56 Joshi PC, Guidot DM. The alcoholic lung: epidemiology, pathophysiology, and potential therapies. Am J Physiol Lung Cell Mol Physiol 2007;292:813-23.

57 Sisson JH, Pavlik JA, Wyatt TA. Alcohol stimulates ciliary motility of isolated airway axonemes through a nitric oxide, cyclase, and cyclic nucleotide-dependent kinase mechanism. Alcohol Clin Exp Res 2009;33:610-6.

58 Szabo G, Saha B. Alcohol's effect on host defense. Alcohol Res 2015;37:159-70.

59 Mehta AJ, Guidot DM, abuse A. Alcohol abuse, the alveolar macrophage and pneumonia. Am J Med Sci 2012;343:244-7.

60 Yeligar SM, Chen MM, Kovacs EJ, Sisson JH, Burnham EL, Brown LAS. Alcohol and lung injury and immunity. Alcohol 2016;55:51-9.

61 Liang Y, Harris FL, Brown LAS. Alcohol induced mitochondrial oxidative stress and alveolar macrophage dysfunction. Biomed Res Int 2014;2014:371593.

62 Kershaw CD, Guidot DM. Alcoholic lung disease. Alcohol Res Heal 2008;31:66-75.

63 del Junco DJ, Fox EE, Camp EA, Rahbar MH, Holcomb JB. Seven deadly SINS in trauma outcomes research. J Trauma Acute Care Surg 2013;75:S97-103.

64 Del Junco DJ, Bulger EM, Fox EE, Holcomb JB, Brasel KJ, Hoyt DB, Grady JJ, Duran S, Klotz $P$, Dubick MA, et al. Collider bias in trauma comparative effectiveness research: the stratification blues for systematic reviews. Injury 2015:46:775-80.

65 Doi SA, Islam N, Sulaiman K, et al. Demystifying Smoker's Paradox: A Propensity Score-Weighted Analysis in Patients Hospitalized With Acute Heart Failure. J Am Heart Assoc 2019;8. 